\section{Fruitless and Semi-dwarf Ruellia simplex R13-5-3, R15-24-17, and R16-1-1}

\author{
Rosanna Freyre ${ }^{1,4}$
}

University of Florida/Institute of Food and Agricultural Sciences, Environmental Horticulture Department, P.O. Box 110670, Gainesville, FL 32611

\section{Zhanao Deng ${ }^{2}$ \\ University of Florida/Institute of Food and Agricultural Sciences, Environmental Horticulture Department, Gulf Coast Research and Education Center, 14625 County Road 672, Wimauma, FL 33598 \\ Victor A. Zayas ${ }^{3}$ \\ University of Florida/Institute of Food and Agricultural Sciences, Environmental Horticulture Department, P.O. Box 110670, Gainesville, FL 32611}

Additional index words. Acanthaceae, aneuploid, haploid, invasive plants, Mexican petunia, plant breeding

Ruellia L. (Acanthaceae) consists of $\approx 300$ species of perennial herbs, shrubs, small trees, and lianas with tropical, subtropical, or temperate distribution (Tripp, 2007). Ruellia simplex Wright (commonly known as Mexican petunia, Mexican bluebell, or Britton's petunia) is a popular landscape plant in the southern United States because of its low maintenance requirements and prolific flowering (Gilman, 1999). It was introduced to Florida sometime before 1940 (Smith et al., 2016) and has naturalized in disturbed uplands and wetlands of seven southern U.S. states (from Florida and South Carolina, and west to Texas), plus the U.S. Virgin Islands, Puerto Rico, and Hawaii [United States Department of Agriculture (USDA), Natrual Resources Conservation Service, 2017]. The University of Florida Institute for Food and Agricultural Science (UF/IFAS) Assessment of the Status of NonNative Plants in Florida's Natural Areas (IFAS Invasive Plant Working Group, 2017) and the Florida Exotic Pest Plant Council (2017) consider $R$. simplex an invasive species and do not recommend its use in Florida.

In 2007, a Ruellia breeding program was initiated at UF/IFAS in Gainesville, FL,

\footnotetext{
Received for publication 26 Feb. 2018. Accepted for publication 1 June 2018 .

The development and evaluation of Ruellia was funded in part by National Institute of Food and Agriculture Hatch Project FLA-ENH-005388 and the National Foliage Foundation.

We thank Gail Bowman, Sofia Chang, Mark Kann, Steven Montalvo, Carly Nelson, and Brian Owens for their technical assistance and Maria Paz for help with statistical analyses.

${ }^{1}$ Research Scientist.

${ }^{2}$ Professor.

${ }^{3}$ Graduate Student.

${ }^{4}$ Corresponding author. E-mail: rfreyre@ufl.edu.
}

aiming to create new cultivars with highly reduced or no fertility for the landscape plant industry. To reduce the spread of $R$. simplex by seed, new cultivars are bred with reduced female fertility (no fruit or very low fruit production, or lack of seed viability) and reduced or lack of male fertility (Freyre et al., 2012a). Mayan ${ }^{\mathrm{TM}}$ Purple ('R10-102', PP24422) and Mayan ${ }^{\mathrm{TM}}$ White ('R10-108', PP25156) were released in 2012 (Freyre et al., 2012b), Mayan ${ }^{\mathrm{TM}}$ Pink ('R10-105Q54', PP26063) in 2013 (Freyre et al., 2014), and Mayan ${ }^{\mathrm{TM}}$ Compact Purple ('R12-2-1', ppp) in 2016 (Freyre et al., 2016). These four cultivars were evaluated by the IFAS Assessment, and their landscape use in Florida was approved. R13-5-3, R1524-17, and R16-1-1 were selected on the basis of their compact and full growth habit, thin leaves, semidwarf plant height, good performance and flowering, and no fruiting. R13-5-3 has purple flowers, R16-1-1 has red-purple flowers, and R15-24-17 has a new flower color for Ruellia, which is white corolla with redpurple throat.

\section{Origin and Ploidy Levels}

The Ruellia simplex clones R13-5-3, R1524-17, and R16-1-1 described here were germinated in 2012, 2014, and 2015, respectively. R13-5-3 is an $F_{2}$ seedling from the cross R9-106 (diploid, white corolla with purple throat) $\times$ 'Chi Chi' (diploid, pink flowers). R15-24-17 is a seedling from the cross R14-2x-WPK3 (diploid, white corolla with red-purple throat) $\times$ R14-4x-WPK3 (tetraploid, white corolla with red-purple throat). R16-1-1 is a seedling from the cross R14-4x-PK1 (tetraploid, pink flowers) $\times$ R14-2x-PK1 (diploid, pink flowers).

Ploidy level determinations were performed at the Interdisciplinary Center for Biotechnology Research at UF as described elsewhere (Zayas et al., 2016). Wild $R$. simplex was used as a diploid control $(2 n=$ $2 x=34$; Daniel et al., 1984) and 'Purple Showers' as tetraploid control. R13-5-3 and R15-24-17 were found to be monoploids ( $n=$ $x=17$ ), which indicates that their origin was likely by haploid parthogenesis in the maternal parents (i.e., individuals develop from egg cells in which meiotic reduction of chromosome number took place). Meanwhile, the DNA peak for R16-1-1 was below the diploid level. This indicates that its origin was likely haploid parthogenesis in the tetraploid maternal parent and, in addition, is an aneuploid (Rieger et al., 1976), with loss of one or more chromosomes absent from the euploid complement $(2 n=2 x=34-$ ?) (Fig. 1).

\section{Description}

To botanically characterize R13-5-3, R15-24-17, and R16-1-1, clones were propagated by cuttings in June 2016 and grown in a research greenhouse in Gainesville, FL. Plants were $\approx 5$ weeks of age when flower corolla diameter, and leaf length and width were measured and descriptions of color for plant parts were determined based on comparison with the Royal Horticultural Society Color Chart (Royal Horticultural Society, 1995). Photos of plants of R13-5-3, R15-2417, and R16-1-1, as well as close-ups of their flowers, are shown (Figs. 2 and 3 ).

R13-5-3. This clone has an upright and full growth habit. Stems are yellow-green (RHS 148A) with a gray-purple tint (RHS 187B) when mature. New growth is lighter in color (RHS 138B) and progressively gets darker with age or light exposure. Stems are between round and square and can become woody near the base of mature plants. Nodes can exhibit swelling and are typically white (RHS 155A), but color can vary based on light exposure and fertility. The nodes and the midrib to approximately one-quarter up the leaf on the abaxial and adaxial surfaces are slightly tomentose. The leaves are oppositely attached and are slightly coriaceous. Leaves are lanceolate and have an entire margin, a narrowly acute apex, and an attenuate base. Leaves are green (RHS 147A) on the adaxial and abaxial sides of the lamina; however, color can vary depending on nutrient soil levels. Venation on both surfaces of the lamina is green (RHS 138B), pinnate, and prominently raised. Average length of mature leaves in R13-5-3 is $13.0 \mathrm{~cm}$, considerably longer than that of Mayan Compact Purple at $8.5 \mathrm{~cm}$ and Mayan Purple at $8.3 \mathrm{~cm}$. Average width of mature leaves for R13-5-3 is $1.0 \mathrm{~cm}$, narrower than Mayan Compact Purple with $1.7 \mathrm{~cm}$ and similar to Mayan Purple with $1.2 \mathrm{~cm}$. Using the formula for area of an ellipse, the average leaf area for R13-5-3 is $11.8 \mathrm{~cm}^{2}$, similar to Mayan Compact Purple with $11.3 \mathrm{~cm}^{2}$ and larger than Mayan Purple with $7.8 \mathrm{~cm}^{2}$.

Flowers in R13-5-3 are pedunculate, complete-perfect, and borne from the axil either solitarily or in a several-flowered cyme. They are actinomorphic and funnel form with five petals, four anthers, and one 


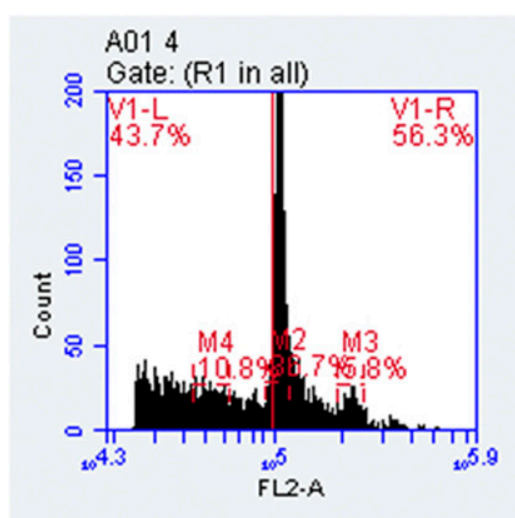

A

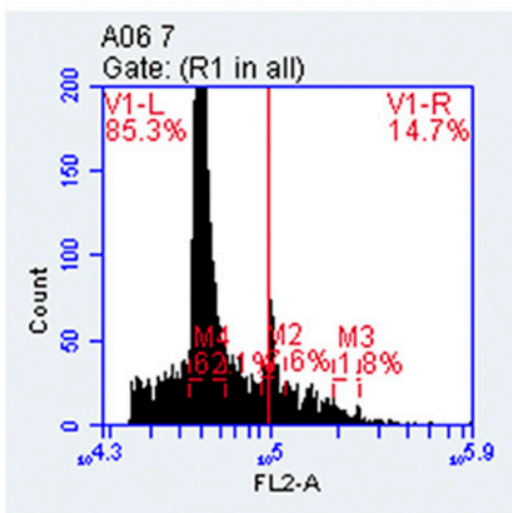

C

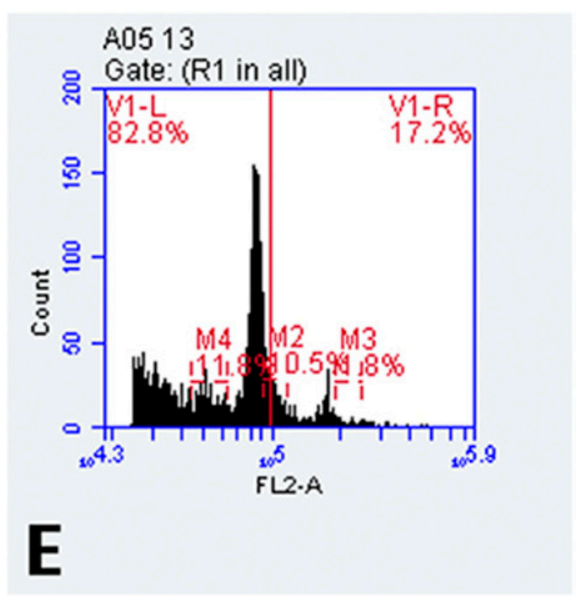

Fig. 1. Flow cytometry graphs for (A) wild Ruellia simplex, (B) 'Purple Showers', (C) R13-5-3, (D) R1524-17, and (E) R16-1-1. These are histograms that display relative fluorescence on the $\mathrm{x}$-axis and the cell count on the y-axis. The red vertical line in each graph indicates the peak for diploid level.

stigma. Glandular trichomes cover the sepal surface of unopened and open flowers. Flowers are purple-violet (RHS 82B) with a darker violet (RHS 83A) corolla tube (Fig. 3A) and last for $1 \mathrm{~d}$, after which the corolla falls. The average corolla diameter (20 flowers of 5-week-old greenhouse plants) is $3.5 \mathrm{~cm}$ in full sun and $4.5 \mathrm{~cm}$ in partial sun, considerably smaller than those of Mayan Compact Purple and Mayan Purple with $5.5 \mathrm{~cm}$, but similar to those of wild $R$. simplex with $4.7 \mathrm{~cm}$.

R15-24-17. This clone has an upright and full growth habit. Stems are yellow-green

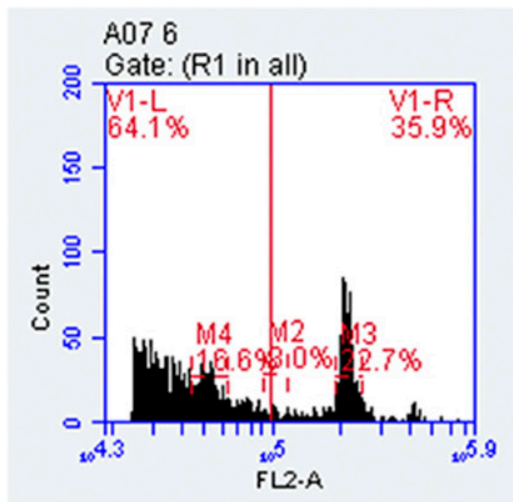

B
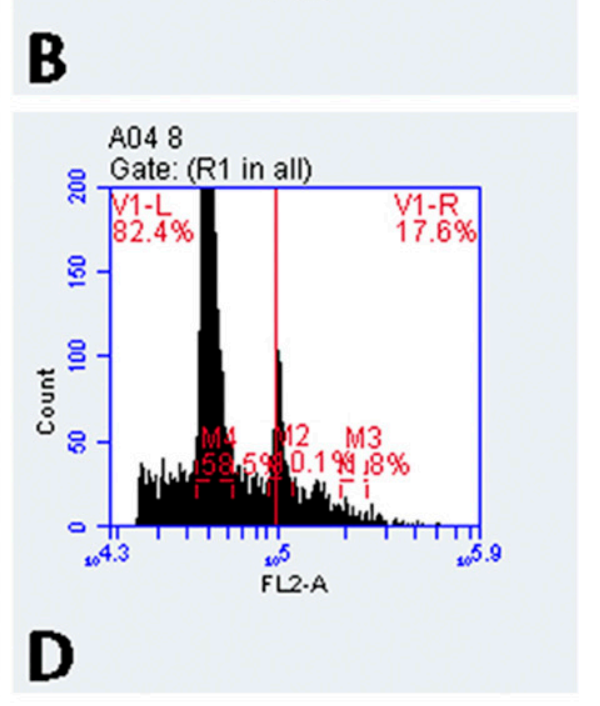

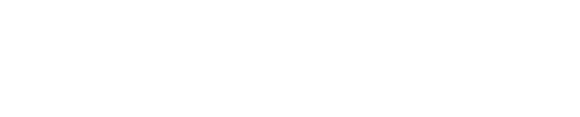




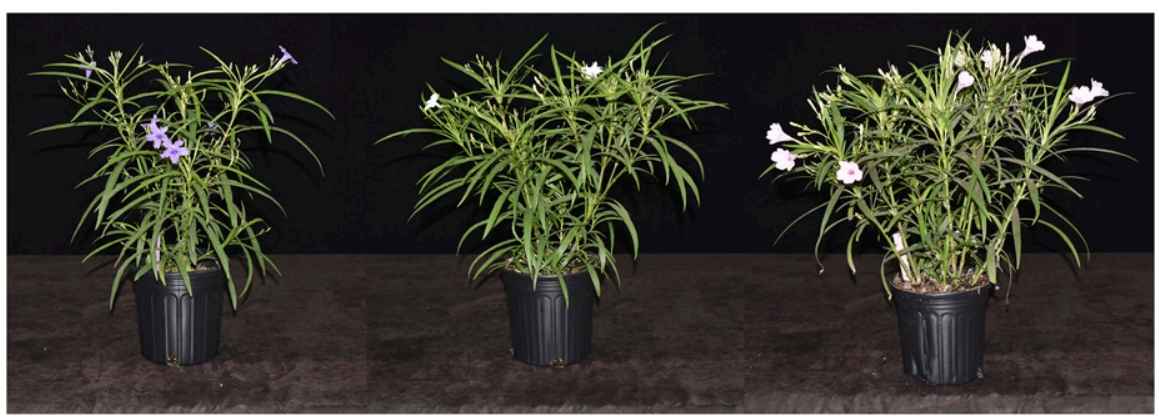

Fig. 2. Seven-week-old plants of Ruellia simplex R13-5-3, R15-24-17, and R16-1-1 (left to right) in 2.8-L pots. Plants were grown in a greenhouse at the University of Florida, Gainesville, FL.

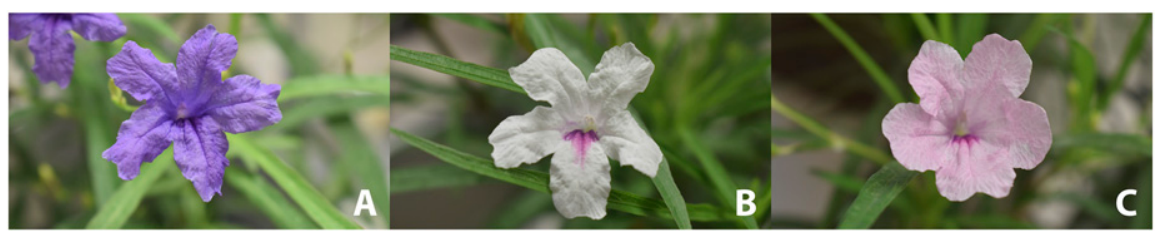

Fig. 3. Flowers on Ruellia simplex: (A) R13-5-3, (B) R15-24-17, and (C) R16-1-1.

(20 flowers of 5-week-old greenhouse plants) is $3.0 \mathrm{~cm}$ in full sun and $4.0 \mathrm{~cm}$ in partial sun, considerably smaller than those of Mayan Compact Purple, Mayan Purple, and wild R. simplex.

\section{Multi-location Replicated Evaluations of Landscape Performance, Flowering, and Fruiting}

A field evaluation using silver plastic mulch was performed on R13-5-3 in summer 2014, and it did not have good performance. Thus, in 2016, the evaluations of R13-5-3, R15-24-17, R16-1-1, and four controls were performed under greenhouse conditions. Three simultaneous experiments were conducted at UF in Gainesville, FL $\left(29.6^{\circ} \mathrm{N}\right.$, $82.36^{\circ} \mathrm{W}$, American Horticulture Society heat zone 10, USDA hardiness zone 9a), at the Plant Science Research and Education Unit (PSREU), Citra, FL $\left(29.4^{\circ} \mathrm{N}, 82.2^{\circ} \mathrm{W}\right.$, AHS heat zone 10, USDA hardiness zone 9a), and at the Gulf Coast Research and Education Center (GCREC), Wimauma, FL $\left(27.45^{\circ} \mathrm{N}\right.$, $82.1^{\circ} \mathrm{W}$, AHS heat zone 10, USDA hardiness zone 9b) (American Horticultural Society, 2012; USDA, 2012). Due to severe twospotted spider mite (Tetranychus urticaeider) infestation at Gainesville, data from that site were not used in the analyses.

The controls included in the trials were wild $R$. simplex, Mayan Purple, Mayan Compact Purple, and the dwarf and fertile 'Southern Star Blue' (PanAmerican Seed Co., West Chicago, IL) to have four clones with different plant heights and growth habits. There was not enough plant material of fertile pinkflowered 'Chi Chi' available at the time; therefore, it could not be included as a control. On 3 Nov. 2016, 18 cuttings for each clone were stuck individually into $15-\mathrm{cm}$ pots with Sunshine LA4 substrate (SunGro Horticulture, Agawam, MA) and were misted every
$5 \mathrm{~s}$ for $10 \mathrm{~min}$ for 2 weeks. Three weeks later, all plants except dwarf 'Southern Star Blue' were pinched. Six plants for each of the seven clones were taken to GCREC on 23 Jan. 2017 and to PSREU on 2 Feb. 2017.

At PSREU, plants were transplanted into industry standard 2.8-L pots filled with Sunshine LA4 substrate. Pots were randomized on top of wire benches, $60 \mathrm{~cm}$ apart in a polycarbonate greenhouse compartment. Plants were fertigated with a water soluble fertilizer $(15 \mathrm{~N}-11.5 \mathrm{P}-12.5 \mathrm{~K})$ at 150 to 200 $\mathrm{mg} \cdot \mathrm{L}^{-1} \mathrm{~N}$ at each irrigation. Greenhouses were maintained at a high of $29^{\circ} \mathrm{C}$ and low of $21^{\circ} \mathrm{C}$. The seventh and last evaluation was on 12 May 2017. At GCREC, plants were transplanted into industry standard 2.8 -L pots filled with Fafard 3B substrate (SunGro Horticulture, Agawam, MA) with about $12 \mathrm{~g}$ of Osmocote Plus $(15 \mathrm{~N}-20.6 \mathrm{~K}-10 \mathrm{~K}$, 5-6 month) slow release fertilizer (The Scotts Co., Marysville, OH). Pots were placed individually and $45 \mathrm{~cm}$ apart in pot holder trays. The trays were randomized and set on the floor covered with black landscape in a greenhouse structure covered with $30 \%$ shade. Average day and night temperature during the trial was $24{ }^{\circ} \mathrm{C}$ (range 7 to $32^{\circ} \mathrm{C}$ ) and $16{ }^{\circ} \mathrm{C}$ (range 1 to $26^{\circ} \mathrm{C}$ ), respectively. Irrigation was by hand, once daily, and no additional fertilizer was applied. The fifth and last evaluation were on 12 Apr. 2017.

At both locations, plants were arranged in a completely randomized design. Starting 2 weeks after transplant, each plant was evaluated every 2 weeks for 14 weeks at PSREU and 10 weeks at GCREC. Plant quality was rated on a scale from 1 to 5 where $1=$ very poor quality, not acceptable, severe leaf necrosis or chlorosis, poor form; 2 = poor quality, not acceptable, large areas of necrosis or chlorosis, poor form; 3 = acceptable quality, somewhat desirable form and color; $4=$ very good quality, very acceptable and desirable color and form; $5=$ excellent quality, perfect condition, premium color and form. Flowering was rated on a 1 to 5 scale where $1=$ no flowers or buds; 2 = buds but no open flowers; $3=1$ to 10 open flowers; $4=11$ to 20 open flowers; $5=$ more than 20 open flowers. Fruiting was rated on a 1 to 5 scale where $1=$ more than 50 fruits; $2=21$ to 50 fruits; $3=11$ to 20 fruits; $4=1$ to 10 fruits; $5=$ no fruits. Average plant quality, maximum plant quality (the highest quality for the plant in each date), average flowering, average fruiting, and average overall quality for each plant at each location were calculated. Average overall quality was calculated by using the mean of the average plant quality, flowering, and fruiting. Plant height and width were measured biweekly for each plant at both locations. Plants that were leaning were propped up to get a full height measurement. The maximum height and maximum width for each plant at each location was calculated. All data were averaged over the days to remove their ordinality and transform them to continuous variables. Data were then analyzed using SAS PROC GLM with mean separation using Tukey's Studentized range test (honestly significant difference) at $P=0.05$ (SAS Institute, version 9.4).

Performance. Data for all the variables evaluated were significantly higher at PSREU than at GCREC, likely because the growing temperatures and plants' nutrition levels were lower at GCREC. For average plant quality, there were highly significant differences between locations and clones, but the interaction location $\times$ clones was not significant. The average plant quality for all clones at PSREU and GCREC was 3.46 and 3.05 , respectively, meaning that all had acceptable to very good quality, color, and form during the whole evaluation period. The average plant quality for each clone across locations is shown in Fig. 4A. Mayan Compact Purple and R15-24-17 were not significantly different, with averages of 3.75 and 3.53, respectively. R-16-1-1 and R13-5-3 had plant quality averages of 3.29 and 3.18 , respectively, and were not significantly different from each other, from R15-24-17 and 'Southern Star Blue' with averages of 3.17, and from Mayan Purple and the wild type, both with 2.95 .

For maximum plant quality per plant there were highly significant differences between locations and clones, but the interaction location $\times$ clones was not significant. The maximum plant quality for all clones was 4.1 and 3.5 , respectively, meaning that all plants had a period of very good quality, color and form during the evaluation period at both locations. The maximum plant quality for each clone across locations is shown in Fig. 4B. The highest rating was for R15-2417 with 4.25, and Mayan Compact Purple and 'Southern Star Blue' were not significantly different, with 4.17 and 3.83 , respectively. Maximum ratings for R16-1-1, the wild type, R13-5-3, and Mayan Purple ranged between 3.67 and 3.45 and were not significantly different from 'Southern Star Blue'. 

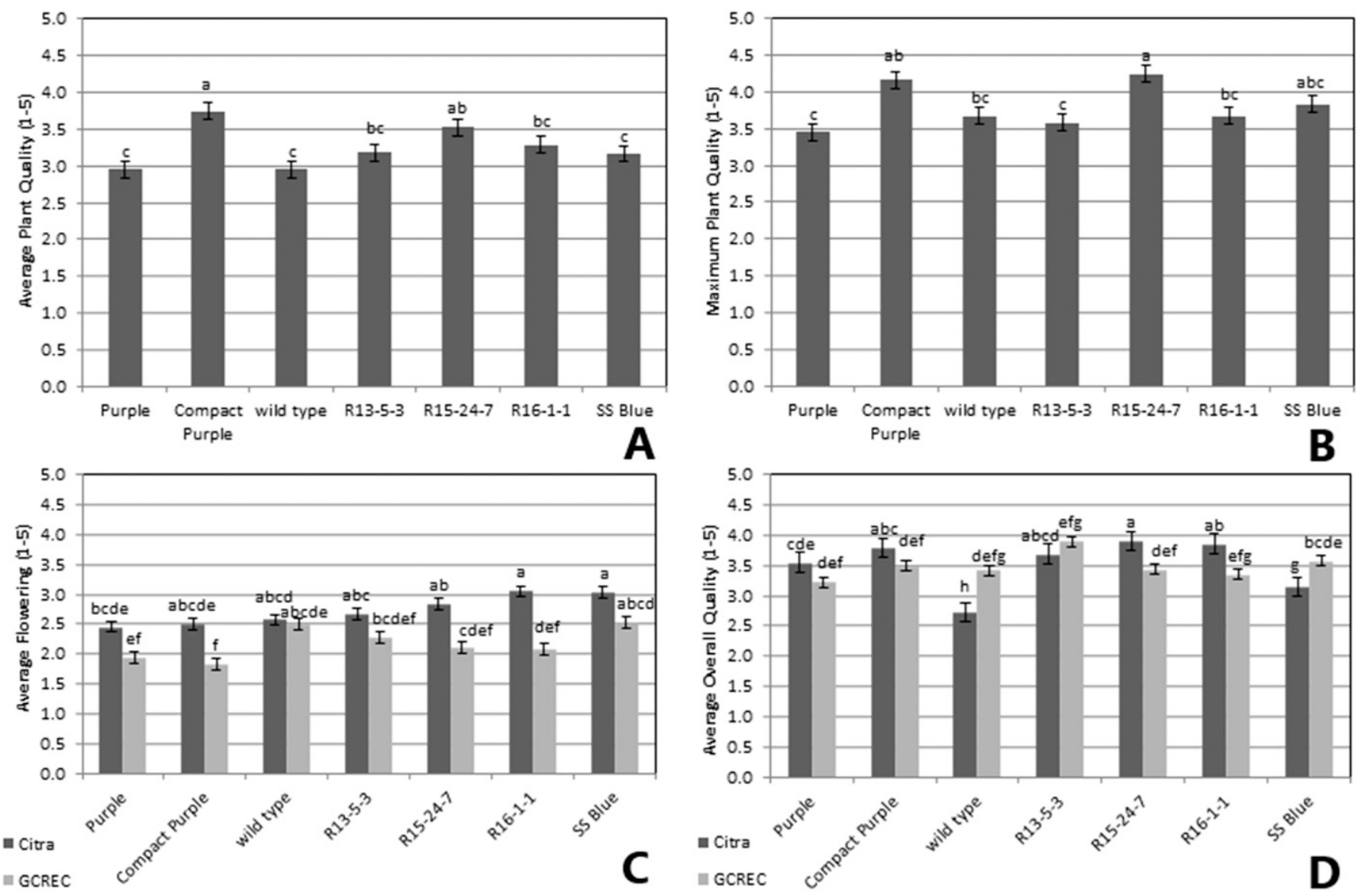

Fig. 4. (A) Average plant quality across two locations (Plant Science Research and Education Unit at Citra, FL, and Gulf Coast Research and Education Center at Wimauma, FL) for Ruellia simplex clones R13-5-3, R15-24-1, R16-1-1, and four controls. (B) Maximum plant quality across locations. (C) Average flowering in two locations. (D) Average overall quality in two locations. The same letter over a bar indicates that the values are not significantly different $(P<0.05)$.
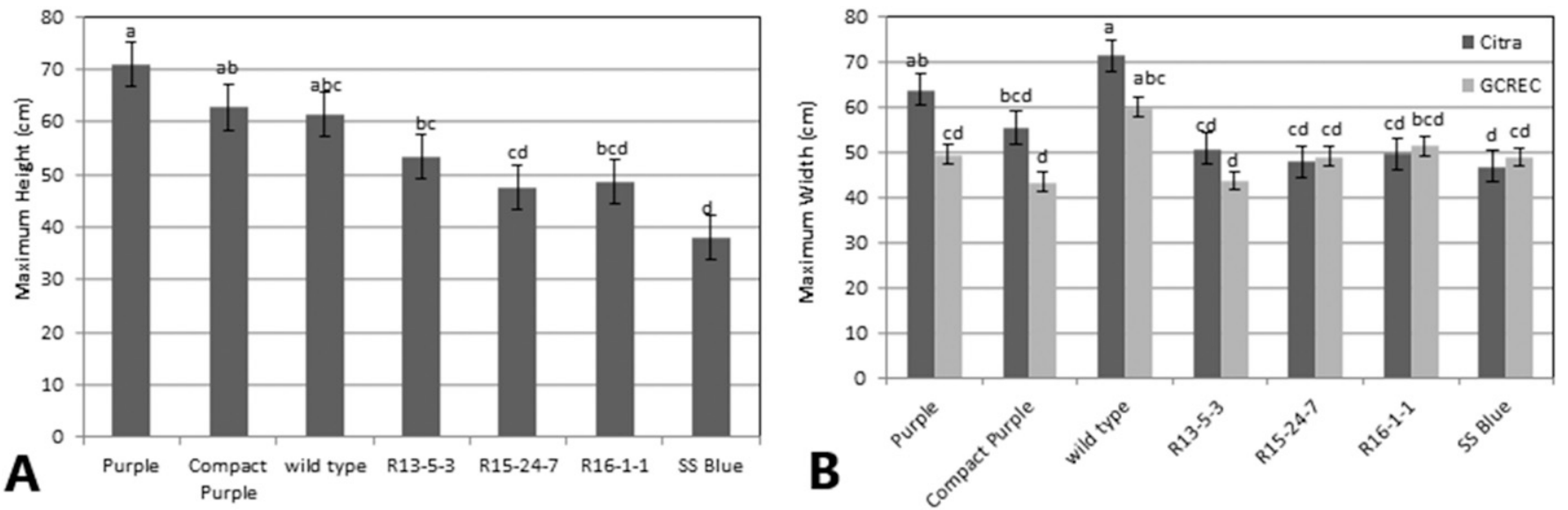

Fig. 5. (A) Maximum height across two locations (Plant Science Research and Education Unit at Citra, FL, and Gulf Coast Research and Education Center at Wimauma, FL) for Ruellia simplex clones R13-5-3, R15-24-17, R16-1-1, and four controls. (B) Maximum width in two greenhouse locations. The same letter over a bar indicates that the values are not significantly different $(P<0.05)$.

For average flowering, there were highly significant differences between locations, clones, and the interaction location $\times$ clone. The average flowering for each clone at both locations is shown in Fig. 4C. At PSREU, the average flowering for all clones was equal or above 2.5, except for Mayan Purple with 2.45. This means that all clones except Mayan Purple had 1 to 10 open flowers at all evaluations. There were no differences between flowering for the clones at PSREU except for R16-1-1 and 'Southern Star Blue' with 3.0 compared with Mayan Purple. At GCREC, all clones had flowering below 2.5 except for 'Southern Star Blue' with 2.53 and the wild type with 2.5 . The only significant differences were between 'Southern Star Blue' and Mayan Compact Purple, which had 1.83 .

For average fruiting, there were highly significant differences among locations, clones, and the interaction location $\times$ clone. As expected, at PSREU, only the fertile wild type and
'Southern Star Blue' set fruit. They were significantly different to each other with averages of 2.43 and 3.22, respectively, meaning between 21 and 50 fruits and between 11 and 20 fruits for each of the two clones. At GCREC, there was no fruiting for any of the clones, including the two fertile clones, likely because of low nutrient levels or temperatures.

For average overall quality, there were highly significant differences among locations, clones, and the interaction location $\times$ clone. 
The average overall quality for each clone at both locations is shown in Fig. 4D. At PSREU, the average overall quality for R15-24-17 was highest with 3.9, and R16-1-1, R13-5-3, and Mayan Compact Purple were all above 3.78 and not significantly different. Mayan Purple with 3.54 was not significantly different from R13-5-3 or Mayan Compact Purple. Fertile 'Southern Star Blue' and the wild type were significantly different from each other and from the other clones with average overall quality of 3.14 and 2.72, respectively. At GCREC, the average overall quality ranged between 3.22 and 3.57, and there were no significant differences between clones.

Vegetative measurements. For maximum height per clone, there were highly significant differences between locations and clones, but the interaction location $\times$ clones was not significant. The maximum height for all clones at PSREU and GCREC was 68.6 and $40.6 \mathrm{~cm}$, respectively. The maximum height per clone across locations is shown in Fig. 5A. Mayan Purple was the tallest clone with a maximum height of $70.9 \mathrm{~cm}$, and it was not significantly different from Mayan Compact Purple and the wild type, with maximum heights of 62.8 and $61.3 \mathrm{~cm}$, respectively. R13-5-3, R15-24-17, and R16-1-1 ranged between 47.4 and $53.5 \mathrm{~cm}$, significantly different from Mayan Purple. As expected, 'Southern Star Blue' had the shortest maximum height with $37.8 \mathrm{~cm}$, and R15-24-17 and R16-1-1 were not significantly different.

For maximum width per clone, there were highly significant differences among locations, clones, and the interaction location $\times$ clones. The maximum width for each clone at both locations is shown in Fig. 5B. At PSREU, the wild type and Mayan Purple were not significantly different, with maximum widths of 71.6 and $64.0 \mathrm{~cm}$, respectively. Mayan Compact Purple with a maximum width of $55.5 \mathrm{~cm}$ was not significantly different from Mayan Purple, R13-5-3, R15-24-17, or R16-1-1. R13-5-3, R15-24-17, and R16-1-1 ranged between 48.0 and $50.8 \mathrm{~cm}$ and were not significantly different from 'Southern Star Blue' with maximum width of $47.0 \mathrm{~cm}$. At GCREC, the only significant difference was between the wild type and R13-5-3 with maximum widths of 60.0 and 43.7, respectively. All the other clones ranged in maximum widths between these two values and were not significantly different from each other.

\section{Female Fertility}

Seed from selfing. As previously mentioned, only wild $R$. simplex and 'Southern Star Blue' produced fruits in the greenhouse at PSREU, and the other clones did not produce any fruit. Their average ratings were 3.8 and 4.4 , respectively (1-10 and $21-50$ fruits per plant, respectively), and were significantly different from each other and from the other five clones. No fruits were observed at GREC, which was likely due to low nutrient levels or temperatures.

Seed obtained from manual hybridizations. Female fertility of R13-5-3, R15-24-17, and R16-1-1 was evaluated by hybridizing them with three male fertile lines: diploid wild $R$. simplex, diploid 'Chi Chi', and tetraploid RU64. Plants were maintained in a greenhouse in Gainesville, FL. Twenty manual hybridizations for each combination were performed as previously described (Freyre et al., 2012b). None of the cross combinations were successful in forming fruit, confirming that R13-5-3, R15-24-17, and R16-1-1 have very low to null female fertility.

\section{Male Fertility and Pollen Stainability}

Seed obtained from manual hybridizations. Male fertility of R13-5-3, R15-24-17, and R161-1 was evaluated by using them as male parents in crosses with three female fertile lines as already described: diploid wild $R$. simplex, diploid 'Chi Chi', and tetraploid RU64. Twenty manual hybridizations for each combination were performed. None of the cross combinations were successful in forming fruit, confirming that R13-5-3, R15-24-17, and R16-1-1 are not successful as male parents.

Pollen viability. To further test male fertility, pollen viability of R13-5-3, R1524-7, and R16-1-1 was evaluated with two methods and compared with known male fertile wild $R$. simplex and 'Chi Chi' and male nonfertile 'Purple Showers'. Six flowers for each clone were collected on 11

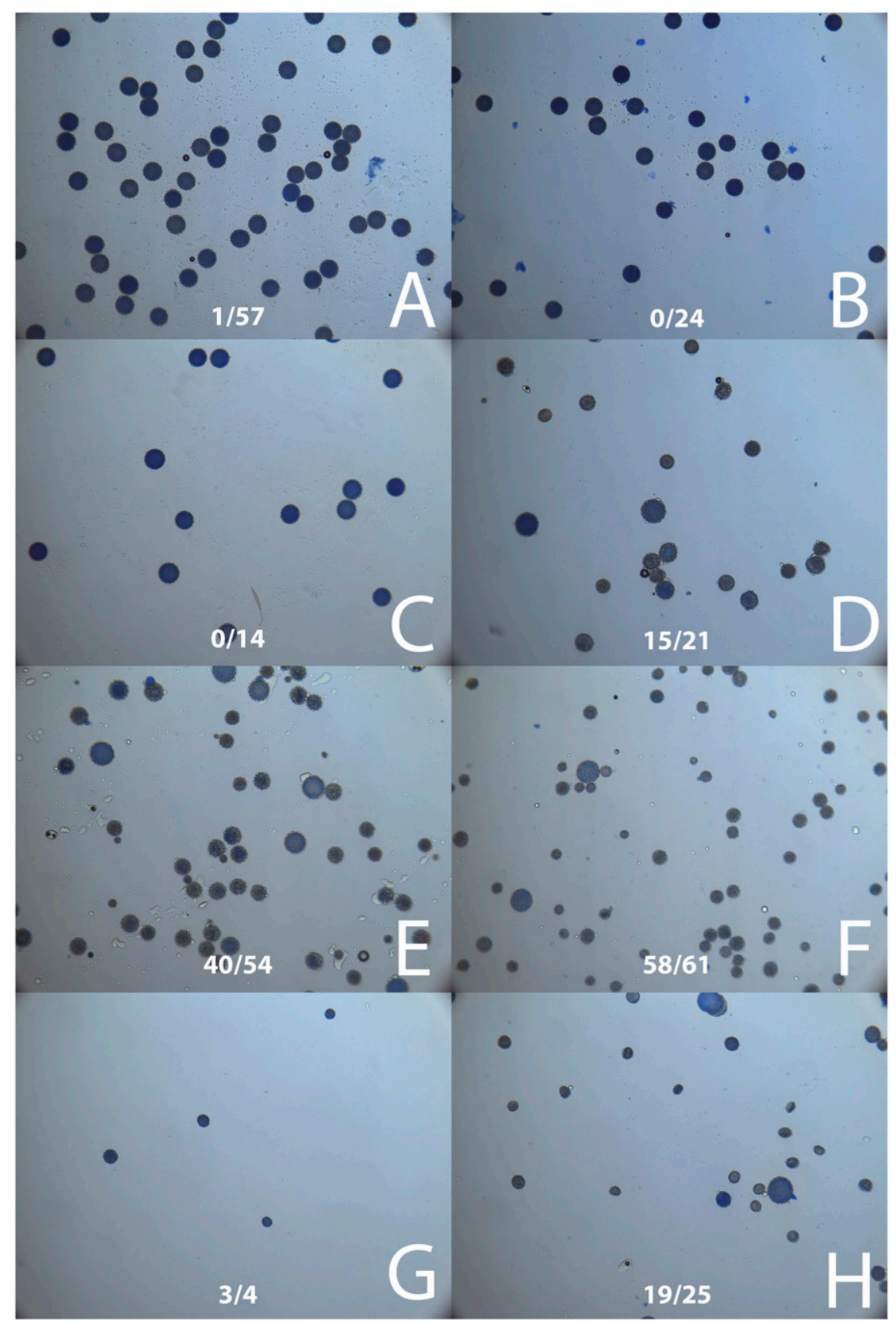

Fig. 6. Pollen grains stained with lactophenol blue; $n=$ number of nonviable pollen grains/total of pollen grains in the sample. (A) Wild Ruellia simplex, $n=1 / 57$; (B) 'Chi-Chi', $n=0 / 24$; (C) 'Southern Star Blue', $n=0 / 14$; (D) 'Purple Showers', $n=15 / 21$; (E) Mayan Purple, $n=40 / 54$; (F) R13-5-3, $n=58 / 61$; (G) $15-24-17, n=3 / 4$; (H) R16-1-1, $n=19 / 25$. 
July 2017 from greenhouse plants grown in Gainesville, FL, at $\approx 9: 00 \mathrm{AM}$, shortly after anthesis to ensure full anther dehiscence and minimal pollen loss. The corolla was carefully detached from each flower, and the four anthers were removed and placed on a microscope slide. Three flowers were prepared for each of the two staining methods. Lactophenol aniline blue stain (LAB) (Remel Lactophenol Aniline Blue, Lanexa, KS) was used for the detection of callose in pollen walls and tubes. The viability of individual pollen grains is considered consistent with the amount of active, stainable cytoplasm. Normal, viable pollen is nearly opaque, with a rich dark blue color. Nonviable pollen is only partially stained or remains mostly unstained with a translucent, light blue color and is typically smaller. Stained pollen grains of smaller size and abnormally shaped grains were also considered nonviable. Additionally, the content of dehydrogenase was tested with a $1 \% 2,3,5$ triphenyl tetrazolium chloride (TTC) solution. To prepare this solution, $0.2 \mathrm{~g}$ of tetrazolium salt (MP Biomedicals, Santa Ana, CA) and $12 \mathrm{~g}$ sucrose (Fisher Science, Nazareth, PA) were dissolved in $20 \mathrm{~mL}$ of sterile distilled water. The $\mathrm{pH}$ of the solution was adjusted to 7.0 for proper staining to occur (Orion VersaStar Pro, Waltham, MA). Normal, viable pollen stains a rich pink or red, whereas nonviable pollen remains unstained. Pollen grains of smaller size and abnormally shaped grains were also considered nonviable.

Two to three drops of each stain were pipetted on each microscope slide containing the excised anthers. The anthers were then agitated in the stain to promote release of pollen grains. Some clones had low amounts of observable pollen, so anthers were opened with a knife blade to maximize number of pollen grains. Pollen on LAB stain was stained for 10 to $30 \mathrm{~min}$, while the TTC pollen were stained for $2.5 \mathrm{~h}$. Then the slides were examined using a light stereoscope at 10× magnification (Leica DM1000, Leica, Allendale, NJ). A total of 25 pollen grains from each sample were counted, if available. A digital microscope camera (Retiga 2000R, Qimaging, Surrey, BC) with 200× was used to obtain photographs of each slide (Fig. 6).

Both LAB and TTC stains gave similar results, so only $\mathrm{LAB}$ results are presented. Wild R. simplex and 'Chi Chi' had $99 \%$ and $98 \%$ pollen viability, respectively. 'Southern Star Blue' had $84 \%$, whereas 'Purple Showers' and Mayan Purple had only 20\% and 11\%. R13-5-3 had considerably less pollen, and most grains were very small or deformed, so viability was estimated at $0.5 \%$. R15-24-17 had no visible pollen on or inside the anthers, so pollen viability was estimated at $0 \%$. R16-1-1 had less viable pollen than 'Purple Showers' and was estimated at $12 \%$ with LAB (and $0 \%$ with TTC).

\section{Conclusions}

In greenhouse potted trials conducted between February and May 2017 in two locations, the selected clones R13-5-3, R1524-17, and R16-1-1 had higher or comparable ratings for average overall plant performance, average plant quality, maximum plant quality, and average flowering as commercial cultivars or wild $R$. simplex. R13-5-3 and R15-24-17 are haploids, whereas R16-1-1 appears to be an aneuploid with chromosome number below diploid. These three clones have a distinctive semidwarf height, full growth habit, and long leaves. R13-5-3 has small purple flowers, R16-1-1 has small redpurple flowers, and R15-24-17 has a new flower color, which is white corolla with red-purple throat. Furthermore, it has been demonstrated that R13-5-3, R15-24-17, and R16-1-1 are fruitless and have very low or null pollen viability. Thus, they are not able to hybridize as a female or male parent with wild Ruellia or other fertile cultivars and will not pose an invasive threat by seed dispersal.

\section{Availability}

U.S. plant patents will be applied for R135-3, R15-24-17, and R16-1-1. Information about plant material, licensing, and propagation agreements can be obtained from the Florida Foundation Seed Producers, Inc., P.O. Box 309, Greenwood, FL 32443.

\section{Literature Cited}

American Horticultural Society. 2012. AHS Plant heat zone map. 15 Sept. 2017. <http://www. ahsgardening.org/gardening-resources/gardeningmaps/heat-zone-map>.

Daniel, T.F., B.D. Parfitt, and M.A. Baker. 1984. Chromosome numbers and their systematic implications in some North-American Acanthaceae. Syst. Bot. 9:346-355.

Florida Exotic Pest Plant Council. 2017. Florida Exotic Pest Plant Council's list of invasive plant species. 14 Sept. 2017. <http://www. fleppc.org/list/list.htm>.

Freyre, R., Z. Deng, G.W. Knox, S. Montalvo, and V. Zayas. 2016. Fruitless Ruellia simplex R122-1 (Mayan Compact Purple). HortScience 51:1057-1061.

Freyre, R. and S.B. Wilson. 2014. Ruellia simplex R10-105-Q54 ('Mayan Pink'). HortScience 49:499-502.

Freyre, R., A. Moseley, S.B. Wilson, and G.W. Knox. 2012a. Breeding and evaluating for landscape performance and fruitlessness in Mexican Petunia (Ruellia, Acanthaceae). HortScience 47:1245-1251

Freyre, R., A. Moseley, S.B. Wilson, and G.W Knox. 2012b. Fruitless Ruellia simplex R10102 ('Mayan Purple') and R10-108 ('Mayan White'). HortScience 47:1808-1814.

Gilman, E.F. 1999. Ruellia brittoniana, Fact Sheet FPS-513. Environmental Horticulture Department, Florida Cooperative Extension Service, Institute of Food and Agricultural Sciences, University of Florida. 14 Sept. 2017. <https:// edis.ifas.ufl.edu/fp513>.

IFAS Invasive Plant Working Group. 2017. IFAS Assessment of Non-Native Plants in Florida's Natural Areas. 14 Sept. 2017. <http://assessment. ifas.ufl.edu/assessments/ruellia-simplex/>.

Rieger, R., A. Michaelis, and M.M. Green. 1976. Glossary of genetics and cytogenetics. Classical and molecular. 4th ed. Springer-Verlag, Berlin, Heidelberg, New York.

Royal Horticulture Society. 1995. RHS colour chart. Royal Horticulture Society, London, UK.

Smith, A.M., S.B. Wilson, C. Reinhardt Adams, R. Freyre, K.V.S. Hupp, A.M. Fox, and R.K. Stocker. 2016. Natural Area Weeds: Mexican Petunia (Ruellia simplex). Environmental Horticulture Department, Florida Cooperative Extension Service, Institute of Food and Agricultural Sciences, University of Florida. 14 Sept. 2017. $<$ http://www.edis.ifas.ufl.edu/ep415>.

Tripp, E.A. 2007. Evolutionary relationships within the species-rich genus Ruellia (Acanthaceae). Syst. Bot. 3:628-649.

U.S. Department of Agriculture. 2012. USDA plant hardiness zone map. 14 Sept. 2017. <http:// planthardiness.ars.usda.gov/PHZMWeb/>.

U.S. Department of Agriculture, Natural Resources Conservation Service. 2012. The PLANTS Database, National Plant Data Center, Baton Rouge, LA. 14 Sept. 2017. <https://www.plants.usda.gov/ java/nameSearch?keywordquery=Ruellia\&mode= sciname\&submitx $=8 \&$ submit. $y=11>$.

Zayas, V.A., A.V. Conner, S. Montalvo, and R. Freyre. 2016. Determination of ploidy levels and breeding of Ruellia simplex. Proc. FL. State Horticulture Soc.129:234-238. 